\title{
POETRY
}

\section{Six hands}

I've never been good with them. My scissoring leaves jagged edges. The sensitivity of my touch on a vein is dull, followed by a puncture too deep or too slow.

Like two neurotic children, when they make a mess of a task they invent an excuse and say the stupid project was my idea appendages are not to blame.

I've never understood why they disguise their motivation from my brain. I imagine handfuls of accomplishment, but my hands do not agree.

Twenty-seven bones, but only eight in the wrist have proper names. Capitate, scaphoid, lunate, trapezium. Triquetrum, trapezoid. Hamate and pisiform. The closer to the centre you get, the more peculiar your shape, the more respect the authorities give you, the more a student has to memorize your name to pass her exam.

This is as far as it goes, my first girlfriend said and nodded to the knot of our clasped hands.

Fifteen, and not even a kiss. Since then my hands have navigated a lot of ground - the cream, the most enduringly supple and enchanting continent of which, my heaven, is your skin.

\section{Jack Coulehan}

Senior Fellow

Center for Medical Humanities,

Compassionate Care, and Bioethics

Stony Brook University

Stony Brook, NY

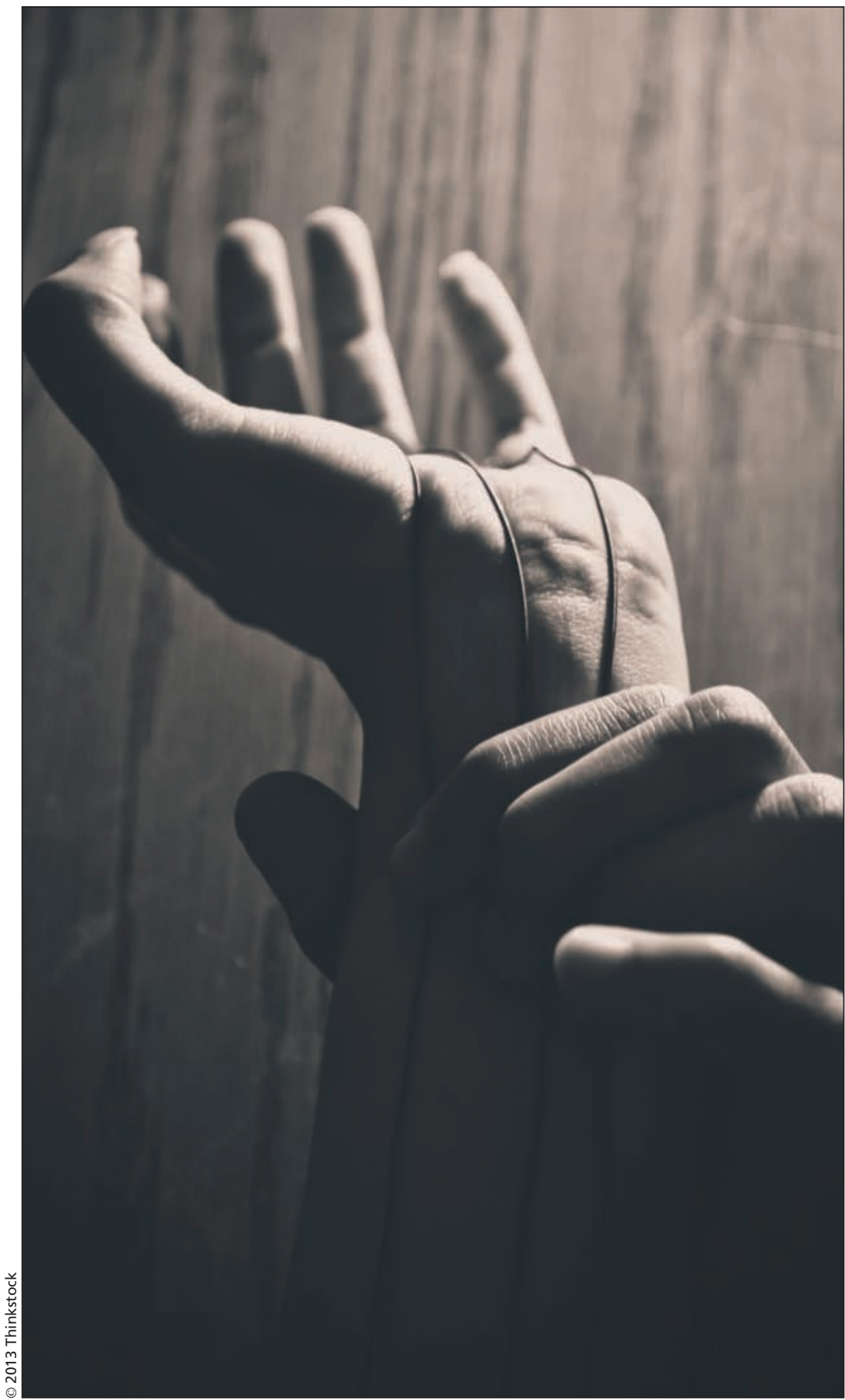

